\title{
O'Connor d'Arlach
}

1) Tem por fim este artigo fazer com que os meus patricios fiquem conhecendo um illustre escriptor boliviano, D. Tomás O'Connor d'Arlach.

Sendo um dos maiores poetas bolivianos na actualidade, é não menos notavel historiador, Membro do Instituto Geographico Argentino de Buenos-Aires, das Sociedades Geographicas de Sucre e La Paz, e entre nós foi distinguido com o logar de Membro do Centro de Sciencias, Letras e Artes de Campinas, creio que por indicação do saudoso Dr. Cesar Bierrenbach.

Farei a analyse de alguns de seus livros que me foram enviados com amaveis dedicatórias.

Fallarei em primeiro logar do historiador, em seguida direi do poeta.

2) O primeiro livro que li de O'Connor d'Arlach, foi «Tiahuanacu».

Extraordinaria foi a impressão que me deixou tão bello trabalho.

Ao percorrer aquellas paginas admiraveis, onde o sabio descreve, com erudição profunda e apaixonado sentimento de artista, as imponentes ruinas da antiquissima cidade andina, tinha a impressão de estar a 3.897 metros acima do nivel do mar, naquellas ruinas que viajantes illustres, escriptores, sabios, artistas, homens de todos os paizes, atraídos pela curiosidade ou por investigações scientificas, visitaram, "... estos grandiósos monumentos que ya eran én tiempo de los Incas, «simbolos cuya significacion se ignoraba y legado de fabulosa antiguedad».

Começa o autor investigando a origem do nome Tiahuanacu.

Descreve em seguida as ruinas. Que bellos quadros!... 
Lembram as mais seductoras passagens de Chateaubriand.

Termina este capitulo com um protesto contra o descuido que se tem com as grandévas ruinas de Tiahuanacu.

No Senado Nacional, em 1905, O'Connor d'Arlach apresentára um projecto de lei declarando as ruinas de Tiahuanacu propriedade do Estado "... pero no para que el Estado las destruya en puentes e calzados, sinó para que las conserve preservándolas del vandalismo».

E é contra os vandalismos que se revolta d'Arlach, coração generoso, alma de artista, que sabe sentir e comprehender as bellezas incomparaveis daquellas vetustas e magestosas ruinas, verendas pela sua antiguidade e alto valor historico e artistico.

Chegamos a um capitulo interessantissimo-antiguidade de Tiahuanacu.

Estuda então as abalisadas opiniões de Marckham; Falb, Lorente e outros sobre o assumpto.

Cita a opinião do sábio Villamil de Rada, que sustenta que o aymara é o idioma primitivo fallado por Adão, e que o Paxaiso esteve naquellas regiões.

Responde, em o capitulo seguinte, á pergunta quem fundou Tiahuanacu?

Trata, em seguida, do modo por que desapareceu Tiahuanacu, e da sua edade.

Fecha o livro com uma das mais empolgantes paginas que li em minha activissima vida de intellectual, a descripção de Tiahuanacu á noite.

Páginas commoventes, admiraveis de sentimentalidade, vivas de cores, tão naturaes que nos fazem crer estarmos vendo com nossos olhos, o que vemos na realidade pelos do poeta, muito mais experientes, olhos de vate, de alma hypersensivel de fino artista.

3) Em seguida, li um outro trabalho muito interessante de O'Connor d'Arlach, sobre a originalissima figura do General Melgarejo.

Não é proposito do Autor escrever-lhe a biographia nem estudar-lhe a psychologia; procura apenas narrar alguns episodios da vida do illustre caudilho.

Difficil é o estudo de tal figura, pois Melgarejo «...era una mezcla extraña de pasiones encontradas, de defectos $v$ de cualidades» 
Não é Melgarejo a unica figura nestas condições na Historia

Desde muito tempo tenho reflectido sobre a extranha figura do tyranno.

Que será um tyranno, um déspota, um caudilho?...

Psychologicamente, parece haver entre todos elles algumas semelhanças - o desinteresse, o amor da glória, o furor do mando...

Comtudo em outros não se encontram estes traços psychologicos: Rosas era usurario; Floriano Peixoto, desprezava a glória; Sylla, abandonou o poder...

Assim sendo, tive sempre que recuar deante desta psychologia extranha, a do tyranno.

Fez, pois, bem O'Connor d'Arlach limitando-se a narrar sómente episódios da vida do grande caudilho.

Para mim, não havia necessidade de explicar os factos psychologicamente, porque sou de parecer que o tyranno é um instrumento da providencia.

Não poderei aqui dar as doutrinas imaginadas para explicar as leis da Historia.

Comtudo, descreio completamente das doutrinas pseudo-scientificas, e da sciencia audaciosa dos Sylvios Roméros e queijandos sabichões que assassinaram a Divindade...

Sinceramente crente, catholico fervoroso, creio na acção da Providencia nos destinos da Humanidade.

Antes de dar a minha opinião sobre o assumpto, quero com o Conde de Vareilles - Sommières (Les Principes fondamentaux du Droit) fazer uma advertencia.

A unidade reina entre os catholicos nos pontos necessarios; nos secundarios temos a liberdade completa de pensamento: in necessariis unitas, in dubiis libertas, in omnibus charitas, é a divisa scientifica dos catholicos.

Uso da minha liberdade, mas si, nas minhas palavras houver alguma cousa contraria aos ensinamentos infalliveis da Egreja, confesso que a minha opinião está errada, e deverá ser considerada como não escripta.

A Providencia, segundo ensina Bergier no seu Dict. de Théologie, é a attenção e a vontade de Deus de conservar a ordem physica e moral que estabeleceu no mundo ao creal-o.

\section{UNIVERSIDADE DE SAO PAÜO \\ Departamento de Cultura e Ação socl-: \\ Biblioteca Central}


Deus intervem nas acções humanas, dirige os nossos destinos, inflúe nos homens e nos factos.

Esta é tambem a opinião do Abbade Bergier que diz que: "Si Dieu ne prenait aucun soin des choses de ce monde, surtout des créatures intelligentes, il serait nul pour nous, et il nous serait fort indifferent de savoir s'il existe ou n'existe pas".

E' verdade que temos o nosso livre arbitrio, mas harmonizado necessariamente com a intẹrvenção da Providencia em nossos destinos.

Deus deixa geralmente o povo escolher os seus dirigentes (réges), o que quer é que haja a autoridade.

Mas, ás vezes, para o castigar ou para recompensál-o, inflúe nos acontecimentos, e entrega o poder a homens máus ou bons.

Os tyrannos são homens vulgares, tão bons ou tão máus como os demais, que ficam em evidencia pela posição sạliente que occupam. defeitos.

Apparecem então claramente as suas qualidades e

Assim Melgarejo, cidadão obscuro, seria um burguez bilioso e borracho, amante da mesa farta, e fazedor de disturbios na mocidade, acalmando-se o seu genio na edade madura.

Collocado porém no poder, foi um caudilho, cujas passagens extraordinarias da vida nos conta O'Connor d'Arlach em encantadoras anedoctas.

Melgarejo, do mesmo modo que a generalidade dos tyrannos, era um inconsciente, um impulsivo, agia por impeto, como por suggestão de uma força superior.

Audacioso até á loucura, tendo comtudo, no meio dos impetos de violencia, sentimentos de bondade, rindo deante do incendio de uma cidade, e chorando deante da desventura de uma mísera creança, amando a bebida, coisa torpe e immunda, amava tambem a poesia e a nobre França: era um mixto de bondade e ferocidade, de homem culto e de bárbaro.

O traço mais sympathico de Melgarejo era o seu horror aos aduladores, aos quaes pregava magnificas peças.

Sinto não poder relatar aqui algumas das deliciosas anedoctas com que O'Connor d'Arlach delicía os leitores de seu magnifico livro. 
Vou comtudo ralatar um facto que muito me impressionou.

Conta O'Connor d'Arlach que Melgarejo, apesar de suas boas relações com o Brasil, e de ter sido, em 1867, condecorado com a Imperial Ordem do Cruzeiro, tinha grandes sympathias pelo heroico tyranno paraguayo - D. F. S. López.

Tendo recebido noticia da morte de López, poucas horas antes de um banquete, levantou o seguinte brinde perante brasileiros e argentinos:

«Debemos admirar y rendir homenaje al valor y al patriotismo, donde quiera que lo encontremos. Los valientes guerreros, los heroes, tienen por patria el mundo todo. No me vengan con nacionalidades cuando se trata de un gran valor o de un gran talento. El general $F$. S. López, no pertence al Paraguay, es una glória de America y de la Humanidad. Bebo, pues, esta copa a la memoria de ese heroe y del gran pueblo paraguayo, a quien han podido vencer, pero no rendir, entre los macacos y los gauchos».

Sabemos como é mal interpretada a guerra do Paraguay, e a quantos perigos desconhecidos, de que nos falla Almeida Nogueira nos seus Estudos Ligeiros, nos ameaçou. A mais de um, estivemos sujeitos.

E' sabido que López queria fugir, por Matto Grosso, para a Bolivia (V. Cantu, Hist. Un., trad. de A. Ennes, p. 425 e P. Larousse), comquanto, no principio da campanha pudesse, tel-o feito (Cantu, cit., p. 424). Imaginemos a hypothese de López, no fim da guerra, alcançar a Bolivia, onde contava um tão perigoso amigo: que seria de nós?...

Bem andou, pois, D. Pedro II, contrariando os que pensavam que a guerra podia terminar em Humaytá.

Resumindo: magnifica impressão me deixou a leitura do livro sobre o General Melgarejo, óbra de alto valor historico, e notavel do ponto de vista literario

4) $\mathrm{Li}$, em seguida, os "Recuerdos de mi tierra", publicados em 1917.

D. Tomás O'Connor d'Arlach, como o nosso Conde de Affonso Celso, distingue-se pela naturalidade. Seus versos são faceis, delicados e sonóros.

Ao lel-os, temos a falsa impressão de que podemos tambem escrever com semelhante singeleza. 
Mas... enganamo-nos, o que já nos fazia observar Montesquien, no seu "Essai sur le goût", ao dizer: "Une des choses qui nous plaît le plus, c'est le naif, mais c'est aussi le style le plus difficile à attraper: la raison en est qu'il est précisément entre le noble et le bas, et est si près du bas, qu'il est très-difficile de le côtoyer toujours sans y. tomber.»

Assim «... a voir les vers de Corneille si pompeux et ceux de Racine si naturels, on ne devineroit pas que Corneille travailloit facilement, et Racine avec peine."

$O$ poeta nasce, falla em verso, sente mais e melhor que os outros homens.

E' o que acontece com O'Connor d'Arlach e com Affonso Celso.

Almas de artista, corações amantissimos e hypersensiveis, tendo uma grande facilidade de expressão, aperfeiçoada pelo estudo, servida por magnifica erudição, seus versos além de profundamente philosophicos e sonóros, agradam-nos pela variedade, pela surpreza, pela delicadeza, por um "...je ne sais quoi», de que nos falla Montesquien, que é, para nós, a cópia fiel da natureza.

Nada ha de mais perfeito, de mais bello, de mais sublime, que a natureza em suas multiplas manifestações. Saber sentil-a, saber descrevel-a, saber contar os proprios sentimentos, sem imitar ninguem, sem copiar os modelos classicos, sem rhetorica, é a missão do poeta, e felizes os que, como O'Connor d'Arlach, na Bolivia, o nosso saudoso Olavo Bilac, o Principe dos poetas brasileiros, e Affonso Celso, entre nós, o conseguem plenamente!

Já dizia Victor Hugo, no seu monumental prefacio de "Cromwell": "Le poete, insistons en ce point, ne doit donc prendre conseil que de la nature, de la vérité, et de l'inspiration, qui est aussi une vérité et une nature.»

Ao ler os versos de O'Connor d'Arlach e de Affonso Celso, temos uma sensação de semelhança entre elle e o nosso mavioso poeta.

E' que as suas psychologias são muito parecidas.

Paes amantissimos, corações de ouro, soffreram, vibrados pela fatalidade, os mesmos e dolorosos golpes nas pessoas dos entes que idolatravam. 
Crentes, sensiveis, nobres, generosos, tudo nelles se assemelha.

Veja-se a dedicatoria do livro:

\section{-A Mi PAÍS NATAL}

Antes de reclinar-me fatigado

en el hombro de nieve del olvidos, te quiero consagrar, oh pueblo amado: estos versos que tú me has inspirado, en prueba de que mucho te he querido.

Que simplicidade, que delicadeza!

Sinto não poder transcrever as bellissimas poesias, Tarija, em que o poeta descreve a cidade natal; Gran Chaco; La Tarijena; El Crepusculo; El Angelus; Dia sin sol e El Aguacero.

Comtudo duas são de grande interesse para nós, pois referem-se a illustre familia brasileira, derivada entre nós do saudoso Dr. Ricardo Gumbleton Duunt, cujo centenario foi tão festejado entre nós com valiosas homenagens de todas as classes sociaes ao insigne varão, que soube honrar, no Brasil,. as tradições gloriosas e seculares de virtude, valor, abnegação, bondade, de sua nobre raça.

São as seguintes:

eCIELO Y TIERRA DE TARIJA.

UNA ESCENA DEL AÑO 1826

Por vez primera el General O'Connor

llega a ocupar la plaza de Tarija;

haciendo alto en la cuesta de Iscayachi, en nuestro valle con amor se fija.

$Y$ respira la brisa perfumada de nuestro claro rio y sus riberas, contempla nuestro cielo de zefiro y nuestras bellas, plácidas praderas.

Y I es el cielo de Nápoles! murmura: mira del rio la una $y$ la otra banda, y al sentir el olor de la tierra húmeda, siento - exclama - tu olor, tierra de Irlanda! 
$Y$ en verdad, Tarija mia, es el de Italia tu cielo, y tu fértil, bello suelo es el de la verde Erin; y tu perpétua Primavera, te torna en una pradera, en un hermoso jardin!

\section{O'CONNOR}

Esta es la Nueva Vega de Granada que en nombre de Castilla, de la colonia en la época pasada, vino a fundar Juan Pórcel de Padilla.

Pero los indomables chiriguanós al la vega invade on, dieron tin con los bravos castellanos y todo en la invasión lo destrujeron.

Y la provincia se llamó Salinas, porque en su rico suelo.

de cloruro de sódio tiene minas,

hoy lleva el nombre di mi heroico abuelo.

Y la Provincia O'Connor se la llama, y es rica y es herm. sa.

¿ quien al verla una vez sola no la ama, si es $\tan$ bella, patriota y generosa?

Su capital, ondina reclinada de rios a la orilla;

con razón Nueva Vega de Granada quiso llamarla Pórcel de Padilla.

Sus tabacos, sus pastos. sus ganados, sus ricas salitreras

y sus variadas aves, sus pescados, sus frutas, sus riquissimas maderas ;

el valor de sus hijos denodados, que fueron en la gu' rra

valientes y magnificos soldados, y en la paz labradores de su tierra;

honrados industriales, e ciudadanos que viven trabajando, que se aman noblemente, como hermanos, a su Dios y a su Patria venerando;

la hace una provincia mas que bella; su porvenir hermoso

es grande. Brille siempre pura estrella de Tarija en el cielo esplendoroso. 


\section{$-206-$}

Estas duas poesias dão uma pallida idéa do esplendidissimo poeta que é O'Connor d'Arlach.

5) Ainda uma óbra histórica de O'Connor d'Arlach: "Los presidentes de Bolivia".

E' um estudo biographico de grande valor

Neste trabalho, estuda, com grande imparcialidade, a vida de todos os chefes de Estado da Bolivia.

6) O ultimo trabalho de O'Connor d'Arlach é "D. Juana Sanchez», novella historica.

E' um trabalho magnifico, referente ao tempo do General Melgarejo.

శ) Creio ter, ainda que muito superficialmente, fallado sobre o historiador e poeta $\mathrm{D}$. Tomás O'Connor d'Arlach, e oxalá concorra este meu insignificante trabalho para fazer conhecido entre nós tão notavel escriptor boliviano, servindo ao mesmo tempo para a nossa approximação com as republicas americanas, por meio do nosso intercambio intellectual.

S. Paulo, 10 de Setembro de 1918.

Braz de Sousa Arruda. Docente da'faculdade de Direito. 